\title{
Involvement of reactive oxygen species and glutathione in gallic acid-induced human umbilical vein endothelial cell death
}

\author{
WOO HYUN PARK and SUHN HEE KIM \\ Department of Physiology, Medical School, Research Institute for Endocrine Sciences \\ Chonbuk National University, JeonJu 561-180, Republic of Korea \\ Received March 20, 2012; Accepted May 11, 2012
}

DOI: $10.3892 /$ or.2012.1842

\begin{abstract}
Gallic acid (GA) has various biological effects including apoptosis. In this study, we investigated the effects of GA on human primary umbilical vein endothelial cells (HUVECs) in relation to cell growth, cell death, reactive oxygen species (ROS) and glutathione (GSH). Treatment with 200 or $400 \mu \mathrm{M}$ GA inhibited the growth of HUVECs at $24 \mathrm{~h}$ and induced cell death, which was accompanied by the loss of mitochondrial membrane potential (MMP; $\Delta \Psi \mathrm{m}$ ). GA decreased or increased ROS levels including $\mathrm{O}_{2}{ }^{\circ-}$. It dose-dependently increased GSH depleted cell numbers. Pan-caspase inhibitor (Z-VAD) did not affect cell growth inhibition, cell death, ROS and GSH levels in GA-treated HUVECs. However, N-acetylcysteine (NAC; a well known antioxidant) and L-buthionine sulfoximine (BSO; an inhibitor of GSH synthesis) enhanced cell growth inhibition, cell death and MMP $(\Delta \Psi \mathrm{m})$ loss in GA-treated HUVECs. NAC decreased general ROS levels in GA-treated HUVECs, but strongly increased $\mathrm{O}_{2}{ }^{-}$levels in these cells. Both NAC and BSO intensified the GSH depletion of GA-treated HUVECs. In conclusion, GA treatment induced growth inhibition and death of HUVECs. The changes of ROS and GSH levels by NAC and BSO influenced cell growth and death in GA-treated HUVECs.
\end{abstract}

Correspondence to: Dr Woo Hyun Park, Department of Physiology, Medical School, Chonbuk National University, JeonJu 561-180, Republic of Korea

E-mail: parkwh71@chonbuk.ac.kr

Abbreviations: GA, gallic acid; HUVEC, human umbilical vein endothelial cells; ROS, reactive oxygen species; MMP $(\Delta \Psi \mathrm{m})$, mitochondrial membrane potential; SOD, superoxide dismutase; FBS, fetal bovine serum; MTT, 3-(4,5-dimethylthiazol-2-yl)-2,5-diphenyltetrazolium bromide; FITC, fluorescein isothiocyanate; $\mathrm{H}_{2}$ DCFDA, 2'7'-dichlorodihydrofluorescein diacetate; DHE, dihydroethidium; GSH, glutathione; CMFDA, 5-chloromethylfluorescein diacetate; Z-VAD-FMK, benzyloxycarbonyl-Val-Ala-Asp-fluoromethylketone; NAC, N-acetyl cysteine; BSO; L-buthionine sulfoximine; PI, propidium iodide

Key words: gallic acid, apoptosis, human umbilical vein endothelial cells, reactive oxygen species, glutathione

\section{Introduction}

Gallic acid (GA) as a polyhydroxylphenolic compound is commonly distributed in various plants, fruits and foods (1) and is very well absorbed in humans (2). Various biological activities of GA have been reported, including antibacterial (3), antiviral (4) and anti-inflammatory effects (5). GA has been shown to be selectively cytotoxic against a variety of cancer cells such as, prostate (6), lung (7-9), gastric, colon, breast, cervical and esophageal cancer $(10,11)$. Apoptosis induced by GA is associated with oxidative stresses derived from reactive oxygen species (ROS), mitochondrial dysfunction and an increase in intracellular $\mathrm{Ca}^{2+}$ level $(12,13)$. Controversially, GA has been reported to have both pro-oxidant and antioxidant properties depending on iron or hydrogen peroxide $\left(\mathrm{H}_{2} \mathrm{O}_{2}\right)$ in medium and plasma $(14,15)$.

ROS, such as $\mathrm{H}_{2} \mathrm{O}_{2}$, superoxide anion $\left(\mathrm{O}_{2}^{-}\right)$and hydroxyl radical $\left({ }^{\circ} \mathrm{OH}\right)$ regulate many important cellular procedures including transcription factor activation, gene expression, differentiation and cell proliferation $(16,17)$. ROS are formed as by-products of mitochondrial respiration or by the action of certain oxidases (18). A change in the redox state of the tissue and cell implies an alteration in the generation or metabolism of ROS. The main metabolic pathways include superoxide dismutase (SOD), expressed as extracellular, cytoplasmic and mitochondrial isoforms (19), which metabolize $\mathrm{O}_{2}{ }^{-}$to $\mathrm{H}_{2} \mathrm{O}_{2}$. Further metabolism by peroxidases, include catalase and glutathione (GSH) peroxidase, yields $\mathrm{O}_{2}$ and $\mathrm{H}_{2} \mathrm{O}(20)$. Cells have antioxidant systems to manage the redox state, which is important for their survival. Excessive production of ROS leads to death in various cell types $(21,22)$.

Vascular endothelial cells (ECs) are implicated in diverse regulatory responsibilities such as vascular permeability for gases and metabolites, vascular smooth muscle tone, blood pressure, blood coagulation, inflammation and angiogenesis (23). The vascular endothelium can experience widespread degrees of oxidative stress, ultimately leading to endothelial dysfunction in cardiovascular diseases via the initiation of EC apoptosis (24). Additionally, angiogenesis involving configuration of new blood vessels from pre-existing vasculature is a crucial event for the transition of tumors from a latent to a malignant state. In spite of the vital role of vascular ECs in tumor biogenesis and progression, the effects of GA on EC death is not completely understood in relation to ROS and 
GSH. Therefore, it is valuable to elucidate the toxicological mechanisms of GA in human primary ECs.

Previously, we demonstrated that GA reduces the growth of human umbilical vein endothelial cells (HUVEC) with an $\mathrm{IC}_{50}$ of approximately $400 \mu \mathrm{M} \mathrm{GA}$ at $24 \mathrm{~h}$ and induced the death of these cells (11). In the present study, we assessed the effects of GA on ROS and GSH levels in GA-treated HUVECs and investigated the effects of NAC (a well known antioxidant) or BSO, an inhibitor of GSH synthesis (25), on GA-treated HUVEC, in relation to cell growth, cell death, ROS and GSH levels.

\section{Materials and methods}

Cell culture. Primary HUVECs from PromoCell GmbH (Heidelberg, Germany) were maintained in a humidified incubator containing $5 \% \mathrm{CO}_{2}$ at $37^{\circ} \mathrm{C}$. HUVECs were cultured in a complete endothelial cell growth medium (ECGM, PromoCell) with $2 \%$ fetal bovine serum (FBS). HUVECs were grown in 100-mm plastic tissue culture dishes (Nunc, Roskilde, Denmark). HUVECs were washed and detached with HEPES-BSS (30 mM HEPES), trypsin-EDTA and trypsin neutralization solution (PromoCell). HUVECs were used between passages 4 and 8 .

Reagents. GA purchased from the Sigma-Aldrich Chemical Co. (St. Louis, MO) was dissolved in ethanol at $200 \mathrm{mM}$ as a stock solution. The pan-caspase inhibitor (Z-VAD-FMK; benzyloxycarbonyl-Val-Ala-Asp-fluoromethylketone) was obtained from R\&D Systems, Inc. (Minneapolis, MN) and was dissolved in DMSO (Sigma) at $10 \mathrm{mM}$ as a stock solution. NAC and BSO were obtained from Sigma-Aldrich Chemical Co. NAC was dissolved in the buffer [20 mM HEPES ( $\mathrm{pH} 7.0)$ ] at $100 \mathrm{mM}$ as a stock solution. BSO was dissolved in water at $100 \mathrm{mM}$ as a stock solution. Based on the previous experiment (26), cells were pretreated with Z-VAD, NAC or BSO for $1 \mathrm{~h}$ prior to treatment with GA. Ethanol $(0.2 \%)$ and DMSO $(0.3 \%)$ were used as a control vehicle.

Growth inhibition assay. The cell growth inhibition effects of drugs were determined by measuring the 3-(4,5-dimethylthiazol2-yl)-2,5-diphenyltetrazolium bromide (MTT, Sigma-Aldrich Chemical Co.) dye absorbance by living cells as previously described (27). In brief, $3 \times 10^{4}$ cells/well were seeded in 96-well microtiter plates (Nunc) for the MTT assay. After exposure to the indicated amounts of GA with or without Z-VAD, NAC or BSO for $24 \mathrm{~h}, 20 \mu \mathrm{l}$ of MTT solution [ $2 \mathrm{mg} / \mathrm{ml}$ in phosphate-buffered saline (PBS)] were added to each well of 96 -well plates. The plates were additionally incubated for $4 \mathrm{~h}$ at $37^{\circ} \mathrm{C}$. Media in plates were withdrawn by pipetting, and $200 \mu \mathrm{l}$ of DMSO was added to each well to solubilize the formazan crystals. Optical density was measured at $570 \mathrm{~nm}$ using a microplate reader (SpectraMAX 340, Molecular Devices Co., Sunnyvale, CA).

Annexin $V$ staining for cell death detection. Apoptosis was determined by staining cells with Annexin V-fluorescein isothiocyanate (FITC) $(\mathrm{Ex} / \mathrm{Em}=488 \mathrm{~nm} / 519 \mathrm{~nm})$, Pharmingen, San Diego, CA; and propidium iodide (PI; Sigma-Aldrich; $\mathrm{Ex} / \mathrm{Em}=488 \mathrm{~nm} / 617 \mathrm{~nm})$. In brief, $1 \times 10^{6}$ cells in a $60-\mathrm{mm}$ culture dish (Nunc) were incubated with the indicated amounts of GA with or without Z-VAD, NAC or BSO for $24 \mathrm{~h}$. Cells were washed twice with cold PBS and then resuspended in $500 \mu 1$ of binding buffer (10 mM HEPES/NaOH pH 7.4, $140 \mathrm{mM}$ $\mathrm{NaCl}, 2.5 \mathrm{mM} \mathrm{CaCl}$ ) at a concentration of $1 \times 10^{6}$ cells $/ \mathrm{ml}$. Five microliters of Annexin V-FITC and PI $(1 \mu \mathrm{g} / \mathrm{ml})$ were then added to these cells, which were analyzed with a FACStar flow cytometer (Becton-Dickinson). Viable cells were negative for both PI and Annexin V. Apoptotic cells were positive for Annexin V and negative for PI, whereas late apoptotic dead cells displayed both high Annexin V and PI labeling. Non-viable cells, which underwent necrosis, were positive for PI and negative for Annexin V.

Measurement of MMP $(\Delta \Psi m)$. MMP $(\Delta \Psi \mathrm{m})$ levels were measured using rhodamine 123 fluorescent dye (SigmaAldrich Chemical Co.; $\mathrm{Ex} / \mathrm{Em}=485 \mathrm{~nm} / 535 \mathrm{~nm}$ ) as previously described (28). In brief, $1 \times 10^{6}$ cells in a $60-\mathrm{mm}$ culture dish (Nunc) were incubated with the indicated amounts of GA with or without Z-VAD, NAC or BSO for $24 \mathrm{~h}$. Cells were washed twice with PBS and incubated with rhodamine $123(0.1 \mu \mathrm{g} / \mathrm{ml})$ at $37^{\circ} \mathrm{C}$ for $30 \mathrm{~min}$. Rhodamine 123 staining intensity was determined by flow cytometry (Becton-Dickinson). An absence of rhodamine 123 from the cells indicated the loss of MMP $(\triangle \Psi \mathrm{m})$ in HUVEC.

Detection of intracellular ROS levels. Intracellular ROS levels were detected by means of an oxidation-sensitive fluorescent probe dye, 2',7'-dichlorodihydrofluorescein diacetate $\left(\mathrm{H}_{2} \mathrm{DCFDA}, \mathrm{Ex} / \mathrm{Em}=495 \mathrm{~nm} / 529 \mathrm{~nm}\right.$; Invitrogen Molecular Probes, OR; ) (29). As $\mathrm{H}_{2}$ DCFDA is poorly selective for $\mathrm{O}_{2}{ }^{--}$, dihydroethidium $(\mathrm{DHE}, \mathrm{Ex} / \mathrm{Em}=518 \mathrm{~nm} / 605 \mathrm{~nm}$; Invitrogen Molecular Probes), which is highly selective for $\mathrm{O}_{2}{ }^{-}$, was used for its detection. In brief, $1 \times 10^{6}$ cells in a $60-\mathrm{mm}$ culture dish (Nunc) were incubated with the indicated amounts of GA with or without Z-VAD, NAC or BSO for $24 \mathrm{~h}$. Cells were then washed in PBS and incubated with $20 \mu \mathrm{M} \mathrm{H}_{2}$ DCFDA or DHE at $37^{\circ} \mathrm{C}$ for $30 \mathrm{~min}$. Dichlorofluorescein (DCF) and dihydroethidium (DHE) fluorescence was detected using a FACStar flow cytometer (Becton-Dickinson). $\mathrm{ROS}$ and $\mathrm{O}_{2}{ }^{--}$levels were expressed as mean fluorescence intensity (MFI), which was calculated by the CellQuest software (Becton-Dickinson).

Detection of the intracellular glutathione levels. Cellular glutathione (GSH) levels were analyzed using 5-chloromethylfluorescein diacetate (CMFDA, Invitrogen Molecular Probes; $\mathrm{Ex} / \mathrm{Em}=522 \mathrm{~nm} / 595 \mathrm{~nm}$ ) as previously described (29). In brief, $1 \times 10^{6}$ cells in a $60-\mathrm{mm}$ culture dish (Nunc) were incubated with the indicated amounts of GA with or without Z-VAD, NAC or BSO for $24 \mathrm{~h}$. Cells were then washed with PBS and incubated with $5 \mu \mathrm{MCMFDA}$ at $37^{\circ} \mathrm{C}$ for $30 \mathrm{~min}$. Chloromethylfluorescein (CMF) fluorescence intensity was determined using a FACStar flow cytometer (Becton-Dickinson). Negative CMF staining (GSH depleted) cells were expressed as the percent of (-) CMF cells.

Statistical analysis. The results represent the mean of at least three independent experiments (mean \pm SD). The data were analyzed using Instat software (GraphPad Prism4, San Diego, CA). The Student's t-test or one-way analysis of variance (ANOVA) with post-hoc analysis using the Tukey's multiple 


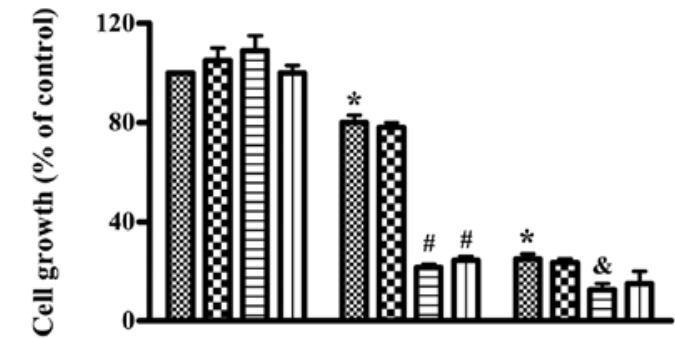

GA $\mu$ M: $\quad 0 \quad 0 \quad 0 \quad 00 \quad 200200200200 \quad 400400400400$ Z-VAD $15 \mu \mathrm{M}:-\quad+-\quad-\quad+\quad-\quad-\quad+\quad-$ NAC 2 mM: - $-+\quad-\quad-\quad-+-\quad-\quad+\quad-$ BSO $10 \mu \mathrm{M}$ : - $-{ }_{-}+-\quad-+-\quad-\quad+$

Figure 1. Effects of Z-VAD, NAC or BSO on cell growth in GA-treated HUVECs. Exponentially growing cells were treated with 200 or $400 \mu \mathrm{M}$ GA for $24 \mathrm{~h}$ following $1 \mathrm{~h}$ pre-incubation with $15 \mu \mathrm{M}$ Z-VAD, 2 mM NAC or $10 \mu \mathrm{M}$ BSO. Cellular growth changes in HUVECs at $24 \mathrm{~h}$, as assessed by MTT assays. ${ }^{*} \mathrm{P}<0.05$ compared with the GA-untreated control group. ${ }^{\#} \mathrm{P}<0.05$ compared with the $200 \mu \mathrm{M}$ GA-treated group. ${ }^{\&} \mathrm{P}<0.05$ compared with the $400 \mu \mathrm{M}$ GA-treated group.

comparison test was used for parametric data. Statistical significance was defined as $\mathrm{P}<0.05$.

\section{Results}

Effects of Z-VAD, NAC or BSO on cell growth in GA-treated HUVECs. We examined the effect of Z-VAD, NAC or BSO on the growth of GA-treated HUVEC using an MTT assay. Treatment with 200 and $400 \mu \mathrm{M}$ GA inhibited the growth of HUVEC about 20 and $70 \%$ at $24 \mathrm{~h}$, respectively (Fig. 1). Treatment with $15 \mu \mathrm{M}$ Z-VAD, $2 \mathrm{mM}$ NAC or $10 \mu \mathrm{M}$ BSO alone did not strongly modify the growth of control HUVECs at $24 \mathrm{~h}$ (Fig. 1). In addition, Z-VAD did not affect HUVEC growth inhibition of 200 or $400 \mu \mathrm{M}$ GA (Fig. 1). However, both NAC and BSO significantly enhanced the growth inhibition of HUVEC by GA (Fig. 1).
Effects of Z-VAD, NAC or BSO on cell death and MMP $(\triangle \Psi m)$ in GA-treated HUVECs. Next, we determined whether GA induces cell death in HUVECs. As shown in Fig. 2A and $\mathrm{B}$, the numbers of Annexin $\mathrm{V}$-staining cells in GA-treated HUVEC were dose-dependently increased at $24 \mathrm{~h}$. Treatment with $400 \mu \mathrm{M}$ GA also increased the numbers of necrotic cells ( $\mathrm{PI}^{+}$and Annexin V-FITC ${ }^{-}$cells) (Fig. 2A and C). Neither Z-VAD, NAC or BSO alone significantly induced control HUVEC death (Fig. 2). Z-VAD did not change the numbers of Annexin V-staining cells in GA-treated HUVECs (Fig. 2A and B). Both NAC and BSO significantly intensified the increased numbers of Annexin V-staining cells by GA (Fig. 2A and B). The strong effect was shown in HUVEC co-treated with $200 \mu \mathrm{M} \mathrm{GA}$ and NAC (Fig. 2A and B). Interestingly, NAC and BSO induced necrotic cell death in HUVECs treated with $200 \mu \mathrm{M}$ GA (Fig. 2A and $\mathrm{C}$ ). NAC also significantly enhanced the increased numbers of necrotic cells by $400 \mu \mathrm{M} \mathrm{GA}$ (Fig. 2A and C).

In addition, GA dose-dependently triggered the loss of MMP $(\triangle \Psi \mathrm{m})$ in HUVEC (Fig. 3). Neither of Z-VAD, NAC or BSO alone induced the MMP $(\Delta \Psi \mathrm{m})$ loss in HUVEC, compared to the GA-untreated control HUVEC (Fig. 3). While Z-VAD did not significantly affect the loss of MMP $(\Delta \Psi \mathrm{m})$, both NAC and BSO enhanced this loss in the GA-treated HUVECs (Fig. 3).

Effects of Z-VAD, NAC or BSO on ROS and GSH levels in GA-treated HUVECs. We assessed whether ROS and GSH levels in GA-treated HUVECs were altered by Z-VAD, NAC or BSO treatment at $24 \mathrm{~h}$. ROS (DCF) levels such as $\mathrm{H}_{2} \mathrm{O}_{2}$ was increased in $200 \mu \mathrm{M}$ GA-treated HUVECs, but was decreased in $400 \mu \mathrm{M}$ GA-treated HUVECs (Fig. 4A and C). NAC did not reduce the basal level of ROS in HUVECs, and BSO increases the ROS level (Fig. 4C). Both Z-VAD and BSO did not significantly alter the ROS (DCF) levels in GA-treated HUVECs whereas NAC strongly decreased them (Fig. 4A and C). Red fluorescence derived from DHE
A
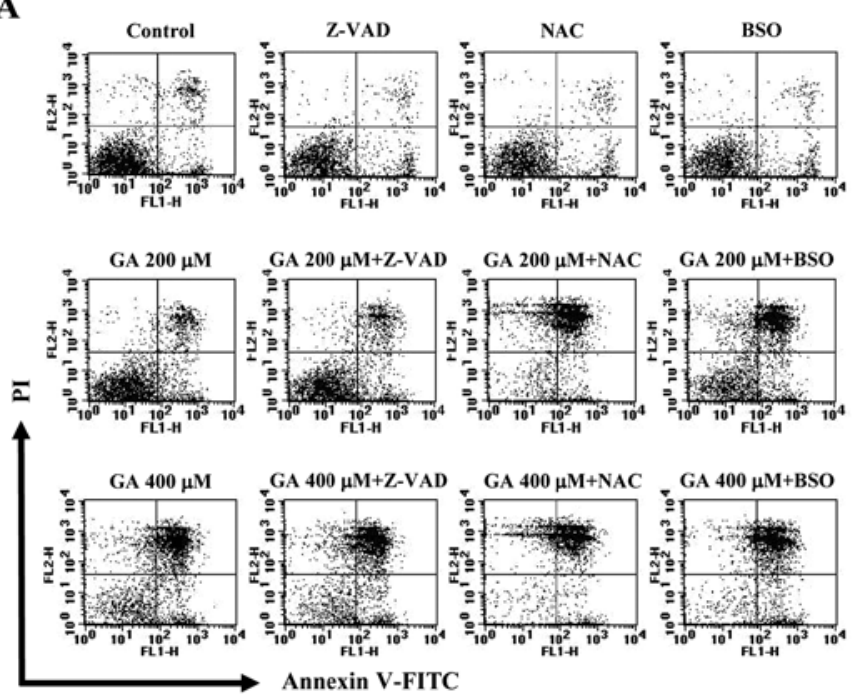

B

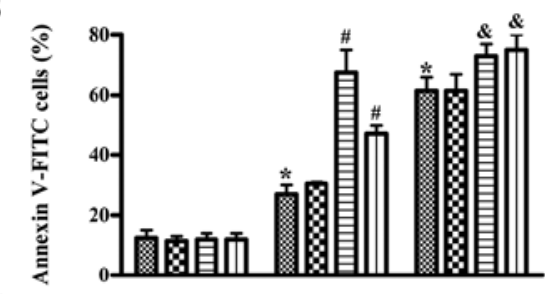

C

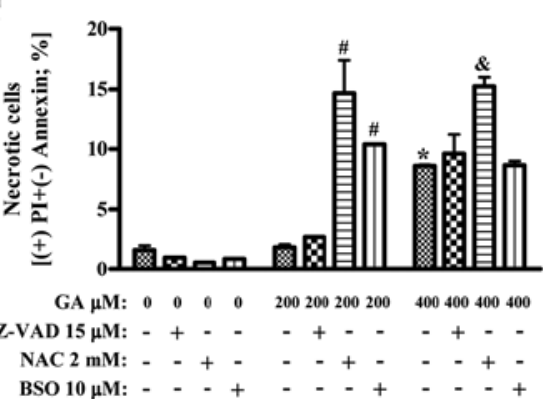

Figure 2. Effects of Z-VAD, NAC or BSO on cell death in GA-treated HUVEC. Exponentially growing cells were treated with 200 or $400 \mu \mathrm{M}$ GA for $24 \mathrm{~h}$ following $1 \mathrm{~h}$ pre-incubation with $15 \mu \mathrm{M} \mathrm{Z-VAD,} 2 \mathrm{mM}$ NAC or $10 \mu \mathrm{M}$ BSO. Annexin V-FITC/PI staining cells were measured with a FACStar flow cytometer. (A) Each figure shows representatives for Annexin V-FITC/PI staining cells. (B) The percentages of Annexin $\mathrm{V}^{+}$staining cells from (A). (C) The percentages of necrotic cells from (A). ${ }^{*} \mathrm{P}<0.05$ compared to GA-untreated control group. ${ }^{\#} \mathrm{P}<0.05$ compared to the $200 \mu \mathrm{M}$ GA-treated group. ${ }^{\&} \mathrm{P}<0.05$ compared to the $400 \mu \mathrm{M}$ GA-treated group. 


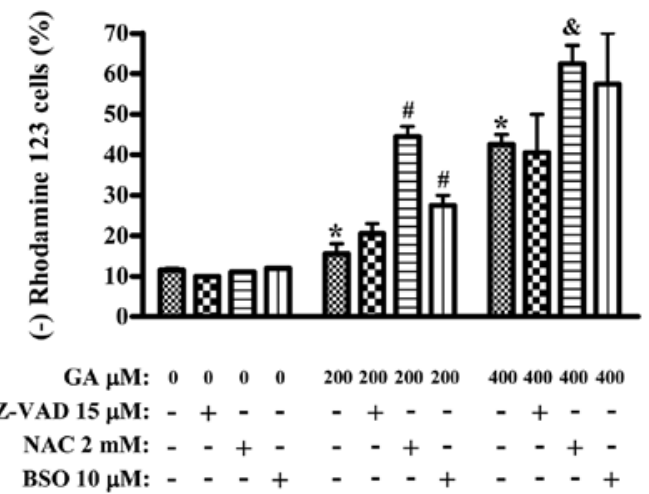

Figure 3. Effects of Z-VAD, NAC or BSO on MMP $(\Delta \Psi \mathrm{m})$ in GA-treated HUVECs. Exponentially growing cells were treated with 200 or $400 \mu \mathrm{M} \mathrm{GA}$ for $24 \mathrm{~h}$ following $1 \mathrm{~h}$ pre-incubation with $15 \mu \mathrm{M} \mathrm{Z}$-VAD, $2 \mathrm{mM}$ NAC or $10 \mu \mathrm{M}$ BSO. MMP $(\Delta \Psi \mathrm{m})$ in HUVEC was measured with a FACStar flow cytometer. The percentages of rhodamine 123 negative [MMP $(\Delta \Psi \mathrm{m})$ loss] cells are displayed. "P $<0.05$ compared to the GA-untreated control group. ${ }^{\#} \mathrm{P}<0.05$ compared to the $200 \mu \mathrm{M}$ GA-treated group. ${ }^{\circledR} \mathrm{P}<0.05$ compared to the $400 \mu \mathrm{M} \mathrm{GA}$-treated group.

reflecting intracellular $\mathrm{O}_{2}{ }^{--}$levels was not altered in the $200 \mu \mathrm{M}$ GA-treated HUVECs but was strongly increased in the $400 \mu \mathrm{M}$ GA-treated HUVECs (Fig. 4B and D). Z-VAD did not alter the $\mathrm{O}_{2}{ }^{--}$levels of GA-treated HUVECs (Fig. 4B and D). Interestingly, $\mathrm{NAC}$ strongly increased $\mathrm{O}_{2}^{-{ }^{-}}$levels in the
200 or $400 \mu \mathrm{M}$ GA-treated HUVECs, and BSO also increased those in the $200 \mu \mathrm{M}$ GA-treated HUVECs (Fig. 4B and D).

GA dose-dependently increased the number of GSH-depleted cells in HUVECs (Fig. 5). Z-VAD did not affect GSH depletion in GA-treated HUVECs (Fig. 5). NAC and BSO significantly enhanced the increased numbers of GSH depleted cells by GA and a strong effect was shown in NAC-treated HUVECs (Fig. 5).

\section{Discussion}

In the present study, we focused on evaluating the effects of GA on the death of HUVECs in relation to ROS and GSH. Treatment with 200 and $400 \mu \mathrm{M} \mathrm{GA}$ inhibited the growth of HUVECs by about 20 and $70 \%$ at $24 \mathrm{~h}$, respectively. This result was similar to the report that GA shows lower cytotoxicity against normal fibroblast and endothelial cells than against cancer cells $(30,31)$. We also observed that GA inhibited the growth of HeLa cervical cancer cells, Calu-6 and A549 lung cancer cells and the doses of $\mathrm{IC}_{50}$ were between 30-150 $\mu \mathrm{M}$ $(9,11)$. Although we do not explain the reason of this different susceptibility, Isuzugawa et al suggested that the different susceptibilities to GA can depend on the catalase contents of each cell (32).

GA is reported to induce apoptosis in prostate cancer cells via mitochondrial dysfunction (13). Likewise, GA induced apoptosis in HUVECs as evidenced by Annexin V staining, and triggered the loss of MMP $(\Delta \Psi \mathrm{m})$. However, Z-VAD did

A

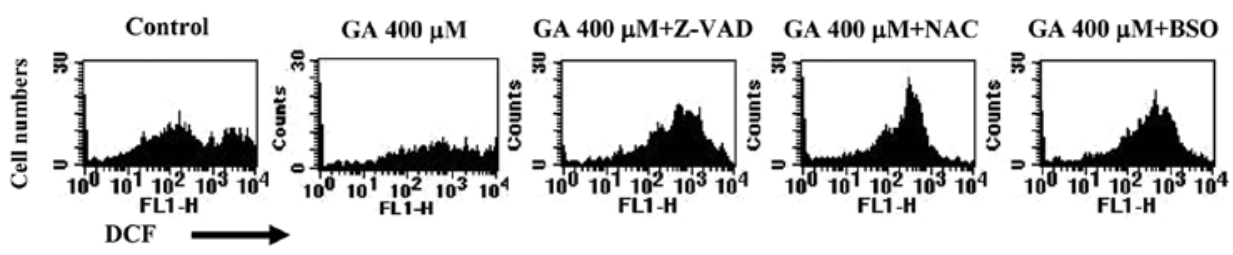

B

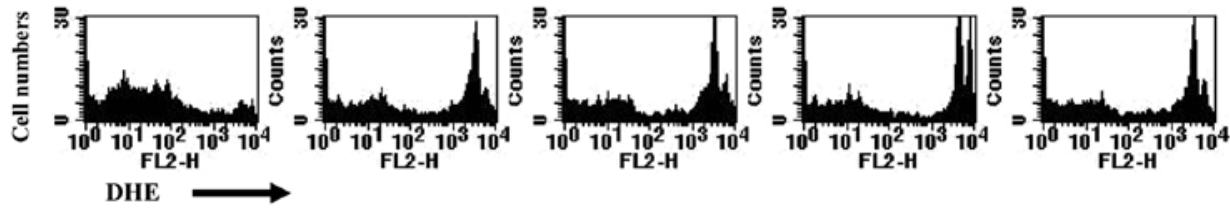

C

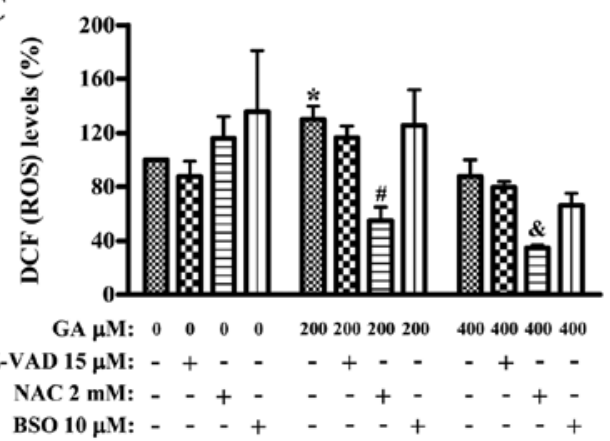

D

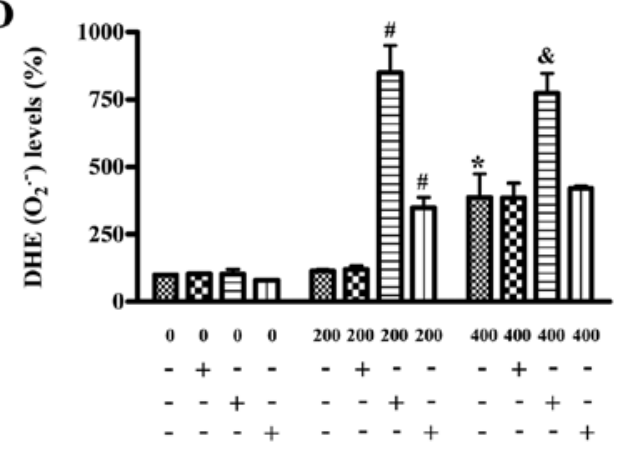

Figure 4. Effects of Z-VAD, NAC or BSO on ROS levels in GA-treated HUVECs. Exponentially growing cells were treated with 200 or $400 \mu \mathrm{M}$ GA for $24 \mathrm{~h}$ following $1 \mathrm{~h}$ pre-incubation with $15 \mu \mathrm{M}$ Z-VAD, $2 \mathrm{mM}$ NAC or $10 \mu \mathrm{M}$ BSO. ROS levels in HUVECs were measured using a FACStar flow cytometer. (A and B) Each histogram as a representative indicates DCF (ROS) and DHE $\left(\mathrm{O}_{2}{ }^{-*}\right)$ levels in each cell group, respectively. (C and D) DCF (ROS) levels (\%) compared with GA-untreated control cells from (A) and DHE $\left(\mathrm{O}_{2}{ }^{\circ}\right)$ levels $(\%)$ compared with GA-untreated control cells from (B). ${ }^{*} \mathrm{P}<0.05$ compared to GA-untreated control group. ${ }^{\#} \mathrm{P}<0.05$ compared to the $200 \mu \mathrm{M}$ GA-treated group. ${ }^{\&} \mathrm{P}<0.05$ compared to the $400 \mu \mathrm{M}$ GA-treated group. 
A

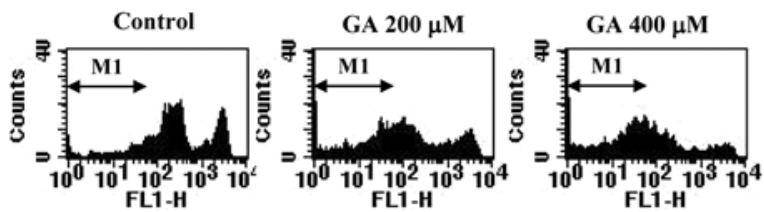

B
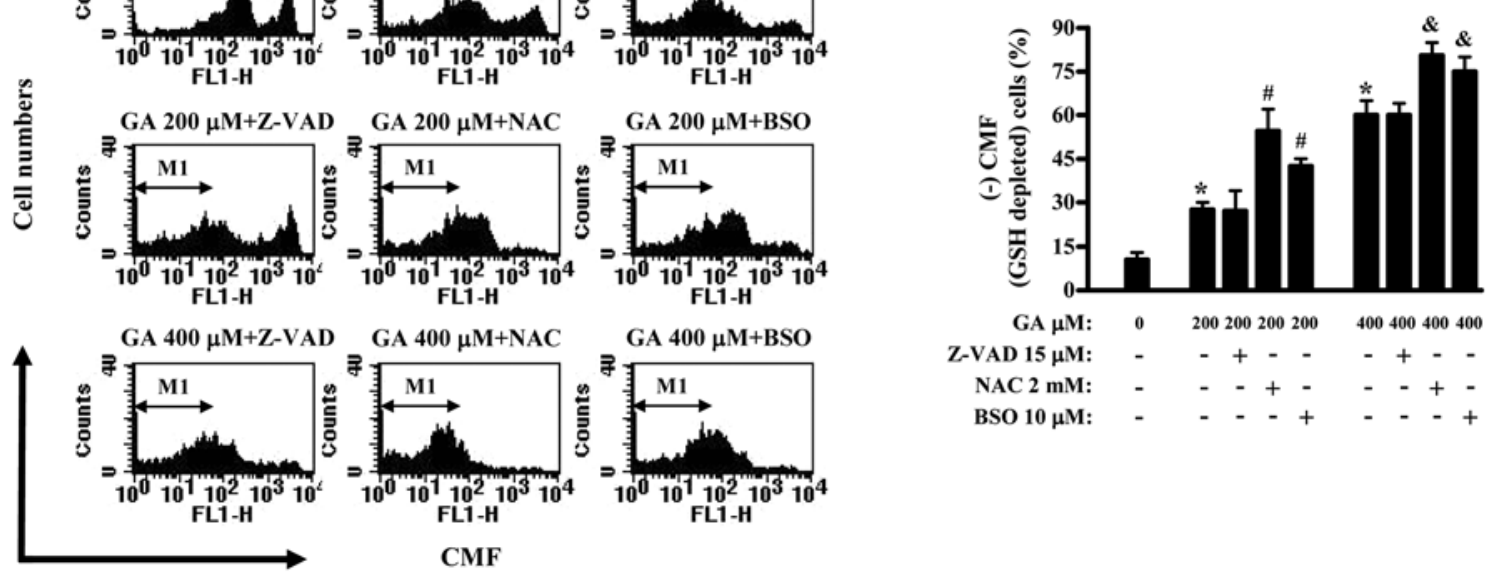

Figure 5. Effects of Z-VAD, NAC or BSO on GSH levels in GA-treated HUVECs. Exponentially growing cells were treated with 200 or $400 \mu \mathrm{M}$ GA for $24 \mathrm{~h}$ following $1 \mathrm{~h}$ pre-incubation with $15 \mu \mathrm{M}$ Z-VAD, $2 \mathrm{mM}$ NAC or $10 \mu \mathrm{M}$ BSO. GSH levels in HUVEC were measured using a FACStar flow cytometer. (A) Each histogram shows CMF (GSH) intensities in HUVECs. M1 indicates (-) CMF (GSH depleted) cells. (B) The percentages of (-) CMF (GSH depleted) cells [M1 region in (A)] are dispayed. ${ }^{~} \mathrm{P}<0.05$ compared with the GA-untreated control group. ${ }^{*} \mathrm{P}<0.05$ compared to the $200 \mu \mathrm{M}$ GA-treated group. ${ }^{\text {\& }} \mathrm{P}<0.05$ compared to the $400 \mu \mathrm{M}$ GA-treated group.

not affect HUVEC death and MMP $(\Delta \Psi \mathrm{m})$ loss of GA. In addition, $400 \mu \mathrm{M} \mathrm{GA}$ increased the numbers of necrotic cells $\left(\mathrm{PI}^{+}\right.$and Annexin V-FITC- cells). These results suggest that GA seemed to inhibit the growth of HUVECs via caspaseindependent apoptosis and/or necrosis.

GA has both pro-oxidant and antioxidant properties $(14,15)$. Increasing evidence suggests that apoptosis induced by GA is associated with oxidative stresses derived from $\operatorname{ROS}(12,13,33)$. According to our results, ROS (DCF) levels such as $\mathrm{H}_{2} \mathrm{O}_{2}$ were increased by $200 \mu \mathrm{M}$ GA-treated HUVECs. However, $400 \mu \mathrm{M}$ GA showing an apoptotic effect decreased the ROS levels. In contrast, $200 \mu \mathrm{M} \mathrm{GA}$ did not after the $\mathrm{O}_{2}^{-{ }^{-}}$levels in HUVECs, whereas $400 \mu \mathrm{M}$ GA significantly increased the $\mathrm{O}_{2}{ }^{-}$level. These results suggest that GA can affect different ROS levels depending on the incubation doses. NAC showing the reduction of ROS (DCF) level in GA-treated HUVEC intensified the growth inhibition, cell death and MMP $(\Delta \Psi \mathrm{m})$ loss in these cells. However, NAC strongly increased the $\mathrm{O}_{2}{ }^{--}$level in these cells. Although NAC decreased the ROS (DCF) levels in GA-treated HUVECs, NAC acted as a pro-oxidant in increasing the $\mathrm{O}_{2}{ }^{-}$ level, thus intensifying HUVEC death. Treatment with BSO showed enhanced effects on the growth inhibition, cell death and MMP $(\Delta \Psi \mathrm{m})$ loss of GA, and it did not significantly alter the ROS (DCF) level in GA-treated HUVECs but increased the $\mathrm{O}_{2}^{-{ }^{-}}$level in HUVECs treated with $200 \mu \mathrm{M}$ GA rather than $400 \mu \mathrm{M}$ GA. Similarly to the results in $\mathrm{O}_{2}{ }^{-}$levels, both NAC and BSO induced necrotic cell death in $200 \mu \mathrm{M}$ GA-treated HUVECs. NAC but not BSO also enhanced the increased numbers of necrotic cells of $400 \mu \mathrm{M}$ GA. Taken together, these results suggest that the alteration of ROS levels by GA is not closely related to HUVEC death, but $\mathrm{O}_{2}{ }^{--}$levels among ROS are involved in HUVEC necrotic cell death. The exact roles of ROS in GA-induced HUVEC death need to be further defined.

It has been reported that the intracellular GSH content has a decisive effect on anticancer drug-induced apoptosis, indicating that apoptotic effects are inversely comparative to GSH content $(34,35)$. Likewise, GA increased the number of GSH depleted cells in HUVECs. Z-VAD did not affect GSH depletion in GA-treated HUVECs. In addition, NAC increased cell death in GA-treated HUVECs significantly increasing the numbers of GSH-depleted cells. Although it is known that NAC containing a thiol group is a GSH precursor, NAC in this study did not act as a GSH precursor. In contrast, we recently demonstrated that NAC significantly prevented GSH depletion in propyl gallate-treated HeLa cervical cancer cells (26). Therefore, NAC may be considered a GSH precursor, depending on the co-incubated agents or cell types. In addition, BSO significantly increased the number of GSH depleted cells in GA-treated HUVEC. Therefore, these results supported the notion that apoptotic effects are inversely comparative to GSH content.

In conclusion, GA inhibited the growth of HUVECs via apoptosis and/or necrosis. The changes of ROS and GSH levels by NAC and BSO affected cell growth and death in GA-treated HUVECs.

\section{Acknowledgements}

This study was supported by a grant from the Ministry of Science and Technology (MoST)/Korea Science and Engineering Foundation (KOSEF) through the Diabetes Research Center at Chonbuk National University (2011-0028226) and the National Research Foundation of Korea Grant funded by the Korean Government (MEST) (2010-0021808).

\section{References}

1. Niemetz R and Gross GG: Enzymology of gallotannin and ellagitannin biosynthesis. Phytochemistry 66: 2001-2011, 2005.

2. Shahrzad S, Aoyagi K, Winter A, Koyama A and Bitsch I: Pharmacokinetics of gallic acid and its relative bioavailability from tea in healthy humans. J Nutr 131: 1207-1210, 2001. 
3. Kang MS, Oh JS, Kang IC, Hong SJ and Choi CH: Inhibitory effect of methyl gallate and gallic acid on oral bacteria. J Microbiol 46: 744-750, 2008

4. Kratz JM, Andrighetti-Frohner CR, Leal PC, Nunes RJ, Yunes RA, Trybala E, Bergstrom T, Barardi CR and Simoes CM: Evaluation of anti-HSV-2 activity of gallic acid and pentyl gallate. Biol Pharm Bull 31: 903-907, 2008.

5. Kim SH, Jun CD, Suk K, Choi BJ, Lim H, Park S, Lee SH, Shin HY, Kim DK and Shin TY: Gallic acid inhibits histamine release and pro-inflammatory cytokine production in mast cells. Toxicol Sci 91: 123-131, 2006.

6. Kaur M, Velmurugan B, Rajamanickam S, Agarwal R and Agarwal C: Gallic acid, an active constituent of grape seed extract, exhibits anti-proliferative, pro-apoptotic and antitumorigenic effects against prostate carcinoma xenograft growth in nude mice. Pharm Res 26: 2133-2140, 2009.

7. Kawada M, Ohno Y, Ri Y, Ikoma T, Yuugetu H, Asai T, Watanabe M, Yasuda N, Akao S, Takemura G, et al: Anti-tumor effect of gallic acid on LL-2 lung cancer cells transplanted in mice. Anticancer Drugs 12: 847-852, 2001.

8. Ohno Y, Fukuda K, Takemura G, Toyota M, Watanabe M, Yasuda N, Xinbin Q, Maruyama R, Akao S, Gotou K, et al: Induction of apoptosis by gallic acid in lung cancer cells Anticancer Drugs 10: 845-851, 1999.

9. You BR and Park WH: Gallic acid-induced lung cancer cell death is related to glutathione depletion as well as reactive oxygen species increase. Toxicol In Vitro 24: 1356-1362, 2010.

10. Faried A, Kurnia D, Faried LS, Usman N, Miyazaki T, Kato H, and Kuwano $\mathrm{H}$ : Anticancer effects of gallic acid isolated from Indonesian herbal medicine, Phaleria macrocarpa (Scheff.) Boerl, on human cancer cell lines. Int J Oncol 30: 605-613, 2007.

11. You BR, Moon HJ, Han YH and Park WH: Gallic acid inhibits the growth of HeLa cervical cancer cells via apoptosis and/or necrosis. Food Chem Toxicol 48: 1334-1340, 2010

12. Inoue $\mathrm{M}$, Sakaguchi N, Isuzugawa $\mathrm{K}$, Tani $\mathrm{H}$ and Ogihara $\mathrm{Y}$ : Role of reactive oxygen species in gallic acid-induced apoptosis. Biol Pharm Bull 23: 1153-1157, 2000.

13. Chen HM, Wu YC, Chia YC, Chang FR, Hsu HK, Hsieh YC, Chen CC and Yuan SS: Gallic acid, a major component of Toona sinensis leaf extracts, contains a ROS-mediated anti-cancer activity in human prostate cancer cells. Cancer Lett 286: 161-171, 2009.

14. Strlic M, Radovic T, Kolar J and Pihlar B: Anti- and prooxidative properties of gallic acid in fenton-type systems. J Agric Food Chem 50: 6313-6317, 2002.

15. Sakagami $\mathrm{H}$ and Satoh K: Prooxidant action of two antioxidants ascorbic acid and gallic acid. Anticancer Res 17: 221-224, 1997.

16. Gonzalez C, Sanz-Alfayate G, Agapito MT, Gomez-Nino A, Rocher A and Obeso A: Significance of ROS in oxygen sensing in cell systems with sensitivity to physiological hypoxia. Respir Physiol Neurobiol 132: 17-41, 2002.

17. Baran CP, Zeigler MM, Tridandapani S and Marsh CB: The role of ROS and RNS in regulating life and death of blood monocytes Curr Pharm Des 10: 855-866, 2004.

18. Zorov DB,Juhaszova M and Sollott SJ: Mitochondrial ROS-induced ROS release: an update and review. Biochim Biophys Acta 1757: 509-517, 2006
19. Zelko IN, Mariani TJ and Folz RJ: Superoxide dismutase multigene family: a comparison of the CuZn-SOD (SOD1), Mn-SOD (SOD2), and EC-SOD (SOD3) gene structures, evolution, and expression. Free Radic Biol Med 33: 337-349, 2002.

20. Wilcox CS: Reactive oxygen species: roles in blood pressure and kidney function. Curr Hypertens Rep 4: 160-166, 2002.

21. Wallach-Dayan SB, Izbicki G, Cohen PY, Gerstl-Golan R, Fine A and Breuer R: Bleomycin initiates apoptosis of lung epithelial cells by ROS but not by Fas/FasL pathway. Am J Physiol Lung Cell Mol Physiol 290: L790-L796, 2006.

22. Simon HU, Haj-Yehia A and Levi-Schaffer F: Role of reactive oxygen species (ROS) in apoptosis induction. Apoptosis 5: 415-418, 2000.

23. Bassenge E: Endothelial function in different organs. Prog Cardiovasc Dis 39: 209-228, 1996.

24. Irani K: Oxidant signaling in vascular cell growth, death, and survival : a review of the roles of reactive oxygen species in smooth muscle and endothelial cell mitogenic and apoptotic signaling. Circ Res 87: 179-183, 2000.

25. Bailey HH: L-S,R-buthionine sulfoximine: historical development and clinical issues. Chem Biol Interact 111-112: 239-254, 1998.

26. Han YH and Park WH: Propyl gallate inhibits the growth of HeLa cells via regulating intracellular GSH level. Food Chem Toxicol 47: 2531-2538, 2009.

27. Park WH, Seol JG, Kim ES, Hyun JM, Jung CW, Lee CC, Kim BK and Lee YY: Arsenic trioxide-mediated growth inhibition in MC/CAR myeloma cells via cell cycle arrest in association with induction of cyclin-dependent kinase inhibitor, p21, and apoptosis. Cancer Res 60: 3065-3071, 2000.

28. Han YH, Kim SZ, Kim SH and Park WH: Arsenic trioxide inhibits growth of As4.1 juxtaglomerular cells via cell cycle arrest and caspase-independent apoptosis. Am J Physiol Renal Physiol 293: F511-F520, 2007.

29. Han YH, Kim SH, Kim SZ and Park WH: Caspase inhibitor decreases apoptosis in pyrogallol-treated lung cancer Calu- 6 cells via the prevention of GSH depletion. Int J Oncol 33: 1099-1105, 2008.

30. Inoue M, Suzuki R, Koide T, Sakaguchi N, Ogihara Y and Yabu Y: Antioxidant, gallic acid, induces apoptosis in HL-60RG cells. Biochem Biophys Res Commun 204: 898-904, 1994.

31. Inoue M, Suzuki R, Sakaguchi N, Li Z, Takeda T, Ogihara Y, Jiang BY and Chen Y: Selective induction of cell death in cancer cells by gallic acid. Biol Pharm Bull 18: 1526-1530, 1995.

32. Isuzugawa $\mathrm{K}$, Inoue $\mathrm{M}$ and Ogihara $\mathrm{Y}$ : Catalase contents in cells determine sensitivity to the apoptosis inducer gallic acid. Biol Pharm Bull 24: 1022-1026, 2001.

33. Serrano A, Palacios C, Roy G, Cespon C, Villar ML, Nocito M and Gonzalez-Porque P: Derivatives of gallic acid induce apoptosis in tumoral cell lines and inhibit lymphocyte proliferation. Arch Biochem Biophys 350: 49-54, 1998.

34. Poot M, Teubert H, Rabinovitch PS and Kavanagh TJ: De novo synthesis of glutathione is required for both entry into and progression through the cell cycle. J Cell Physiol 163: 555-560, 1995.

35. Schnelldorfer T, Gansauge S, Gansauge F, Schlosser S, Beger HG and Nussler AK: Glutathione depletion causes cell growth inhibition and enhanced apoptosis in pancreatic cancer cells. Cancer 89: 1440-1447, 2000. 